\title{
Dopaminergic Neurotransmission in the Nucleus Accumbens Modulates Social Play Behavior in Rats
}

\author{
Antonia Manduca', Michela Servadio', Ruth Damsteegt ${ }^{2}$, Patrizia Campolongo ${ }^{3}$, Louk JMJ Vanderschuren ${ }^{4}$ \\ and Viviana Trezza*,I \\ 'Department of Science, Section of Biomedical Sciences and Technologies, University 'Roma Tre', Rome, Italy; 'Department of Translational \\ Neuroscience, Brain Center Rudolf Magnus, University Medical Center Utrecht, Utrecht, The Netherlands; ${ }^{3}$ Department of Physiology and \\ Pharmacology, Sapienza University of Rome, Rome, Italy; ${ }^{4}$ Department of Animals in Science and Society, Division of Behavioural Neuroscience, \\ Faculty of Veterinary Medicine, Utrecht University, Utrecht, The Netherlands
}

\begin{abstract}
Social play behavior is a highly rewarding form of social interaction displayed by young mammals. Social play is important for neurobehavioral development and it has been found to be impaired in several developmental psychiatric disorders. In line with the rewarding properties of social play, we have previously identified the nucleus accumbens (NAc) as an important site of action for endocannabinoid and opioid modulation of this behavior. NAc dopamine has a well-known role in certain components of reward processes, such as incentive motivation. However, its contribution to the positive emotional aspects of social interactions is less clear. Therefore, we investigated the role of dopaminergic neurotransmission in the NAc in social play behavior in rats. We found that intra-NAc infusion of the dopamine releaser/ reuptake inhibitor amphetamine increased social play behavior that was dependent on activation of both DI and D2 dopamine receptors. This increase in social play behavior was mimicked by intra-NAc infusion of the dopamine receptor agonist apomorphine, but not of the dopamine reuptake inhibitor GBR-12909. Blockade of either DI or D2 NAc dopamine receptors reduced social play in animals highly motivated to play as a result of longer social isolation before testing. Last, blockade of NAc dopamine receptors prevented the playenhancing effects of endocannabinoid and opioid receptor stimulation. These findings demonstrate an important modulatory role of NAc dopaminergic neurotransmission in social play. Thus, functional activity in the mesolimbic dopamine pathway plays an important role in adaptive social development, whereas abnormal NAc dopamine function may underlie the social impairments observed in developmental psychiatric disorders such as autism, attention deficit hyperactivity disorder or early-onset schizophrenia.
\end{abstract}

Neuropsychopharmacology (2016) 4I, 22I5-2223; doi: 10.1038/npp.2016.22; published online 2 March 2016

\section{INTRODUCTION}

Social interactions with peers are crucial for the emotional well-being of young mammals. One of the most characteristic interactions is social play behavior, known to be important for the development of physical, cognitive, and social capacities of animals and humans (Panksepp et al, 1984; Pellis and Pellis, 2009). Importantly, social play behavior is profoundly impaired in several psychiatric disorders that manifest in childhood and adolescence (Alessandri, 1992; Jordan, 2003).

Social play is highly rewarding, as indicated by operant and place conditioning experiments in rats and primates (Achterberg et al, 2016; Calcagnetti and Schechter, 1992; Falk, 1958; Ikemoto and Panksepp, 1992; Normansell and Panksepp, 1990; Trezza et al, 2009). Therefore, it is not surprising that social play is modulated by neurotransmitters involved in reward and motivation (Trezza et al, 2010). For example, opioid agonists and drugs that enhance

*Correspondence: Dr $\vee$ Trezza, Department of Science, Section of Biomedical Sciences and Technologies, University 'Roma Tre', Viale G. Marconi 446, Rome 00 |46, Italy, Tel: +39 065733 6343, Fax: +39 06 5733 6365, E-mail: viviana.trezza@uniroma3.it

Received 16 November 2015; revised 25 January 2016; accepted 4 February 2016; accepted article preview online 10 February 2016 endocannabinoid signaling by interfering with endocannabinoid deactivation increase social play (Trezza et al, 2010). There are several reasons to hypothesize that dopaminergic neurotransmission also has a modulatory role in social play: (1) dopamine plays an important role in certain components of reward processes, such as incentive motivation, incentive salience, and reward prediction (Kelley, 2004; Barbano and Cador, 2007; Berridge, 2007; Salamone and Correa, 2012; Keiflin and Janak, 2015); (2) dopamine utilization increases during social play (Panksepp, 1993); (3) systemic administration of dopamine receptor antagonists reduces social play (Beatty et al, 1984; Niesink and Van Ree, 1989; Siviy et al, 1996; Trezza and Vanderschuren, 2009); (4) neonatal 6hydroxydopamine lesions, which induce profound depletion of striatal dopamine, alter the structure of social play behavior (Pellis et al, 1993); and (5) enhancing dopaminergic activity by blockade of the dopamine transporter increases the motivation for social play (Achterberg et al, 2016). However, contrary to the expectation that drugs that increase dopaminergic neurotransmission would then enhance social play, inconsistent effects have been reported after systemic treatment with dopamine receptor agonists or dopamine reuptake inhibitors (Achterberg et al, 2014; Beatty et al, 1984; Niesink and Van Ree, 1989; Siviy, 1998; Siviy et al, 1996; 
Vanderschuren et al, 2008). This inconsistency may be the result of the fact that simultaneous increase of dopaminergic activity in multiple brain areas following systemic administration of dopaminergic drugs has distinct effects on social play, whereas optimal levels of dopamine functioning in discrete brain regions may be necessary during social play.

Previous studies have shown that the nucleus accumbens (NAc), a brain region widely implicated in reward and motivation (Berridge and Kringelbach, 2008; Everitt and Robbins, 2005; Floresco, 2015), modulates the positive subjective properties of social play behavior in rats (Gordon et al, 2002; Trezza et al, 2011, 2012; van Kerkhof et al, 2013, 2014; Vanderschuren et al, 1995b). Interestingly, peer-peer interactions in 4-week-old rats increase dopamine activity in the NAc (Robinson et al, 2011). Furthermore, rats from the Fischer 344 strain, known to be less playful than other inbred strains, showed less evoked dopamine release and altered dopamine turnover in the NAc (Siviy et al, 2011). On the basis of these findings, and given the well-established role of NAc dopamine in incentive motivation, salience, and reward prediction, we hypothesized that the modulatory effects of dopaminergic neurotransmission on social play are mediated within the NAc. To test this hypothesis, we assessed how manipulation of dopaminergic neurotransmission in the NAc affects social play behavior in rats. Dopamine signaling in the NAc occurs through D1 and D2 receptors that are for the most part localized on output neurons with distinct anatomical and cytochemical characteristics (Voorn et al, 2004; Gerfen and Surmeier, 2011). Stimulation of both dopamine D1 and D2 receptors is thought to contribute to reward processes (Volkow and Morales, 2015), although distinct roles for D1 vs D2 receptors have also been proposed (see, eg, Kravitz et al, 2012). Therefore, we separately assessed the contribution of NAc dopamine D1 and D2 receptors in social play behavior. Furthermore, as motivation for social play depends on dopaminergic neurotransmission (Achterberg et al, 2016), we also investigated the role of NAc dopaminergic neurotransmission in social play in animals that differed in their motivation and baseline levels of social play as a result of a longer period of social isolation before testing (Niesink and van Ree, 1989; Vanderschuren et al, 1995a, 2008). Last, as endogenous opioids (Trezza et al, 2011) and endocannabinoids (Trezza et al, 2012) in the NAc mediate social play behavior, and part of the rewarding properties of cannabinoid and opioid drugs involves limbic dopamine-dependent processes (Gardner, 2005; van Ree et al, 1999), we also determined whether NAc dopaminergic neurotransmission underlies the play-enhancing effects mediated by endocannabinoids and opioids.

\section{MATERIALS AND METHODS}

\section{Animals}

Male Wistar rats (Charles River Laboratories) arrived in the animal facility at 21 days of age and were housed in groups of five in Macrolon cages $\left(43 \times 26 \times 20 \mathrm{~cm}^{3}\right)$ under controlled conditions (temperature $21 \pm 1{ }^{\circ} \mathrm{C}, 60 \pm 10 \%$ relative humidity and $12 / 12 \mathrm{~h}$ light cycle with lights on at $0700 \mathrm{~h}$ ). Food and water were available ad libitum. Animals were experimentally naive and were used only once. All procedures were approved by the Italian Ministry of Health and the Animal Ethics Committee of Utrecht University and were performed in agreement with the European Community Guideline 86/609/ EEC and European Community Directive 2010/63/EU.

\section{Surgery}

The surgical procedures were based on our previous experiments (Achterberg et al, 2015; Trezza et al, 2011, 2012). At 28 days of age, rats were anesthetized with sodium pentobarbital (35 mg/kg, i.p.; Sigma Aldrich) and positioned into a stereotaxic apparatus (David Kopf Instruments). Guide cannulae (Cooper's Needleworks) were implanted bilaterally, aimed $1.0 \mathrm{~mm}$ above the $\mathrm{NAc}$, at the border between the core and shell subregions (coordinates: AP+1.5 mm; $\mathrm{ML} \pm 1.9 \mathrm{~mm}$; DV-7.0 mm; Trezza et al, 2011, 2012 Supplementary Figure S1). Cannulas were secured with stainless steel screws and dental acrylic; wire stylets (Cooper's Needleworks) were inserted into the guide cannulas to maintain patency. After surgery, the rats were individually housed and allowed to recover for 4 days. On the fifth day, they were rehoused in groups of five with their original cage mates. Behavioral testing began 1 week after surgery.

\section{Drugs}

D-amphetamine sulfate (Research Biochemicals International), the nonselective dopamine receptor agonist (R)(-)-apomorphine hydrochloride (Tocris Bioscience), the nonselective dopamine receptor antagonist cis-(Z)-flupenthixol dihydrochloride (Sigma Aldrich), the dopamine D1 receptor antagonist $\mathrm{R}(+)-\mathrm{SCH}-23390$ hydrochloride (Sigma Aldrich), the dopamine D2 receptor antagonist eticlopride hydrochloride (Sigma Aldrich), and the opioid receptor agonist morphine (OPG) were dissolved in saline. The dopamine reuptake inhibitor GBR-12909 (National Institute of Mental Health's (NIMH) Chemical Synthesis and Drug Supply Program) was dissolved in distilled water. The anandamide hydrolysis inhibitor URB597 (NIMH Chemical Synthesis and Drug Supply Program) was dissolved in $5 \%$ Tween $80 / 5 \%$ polyetylene glycol/saline.

Drugs were infused into the NAc, except URB597 and morphine that were given intraperitoneally (i.p.) and subcutaneously (s.c.) 2 and $1 \mathrm{~h}$, respectively, before testing.

\section{Infusion Procedures and Histological Confirmation of Injection Sites}

Bilateral infusions of drugs or an equivalent volume $(0.3 \mu \mathrm{l})$ of the corresponding vehicle were made as described in our previous studies (Trezza et al, 2011, 2012). After infusions, the animals were left in a holding cage for $5 \mathrm{~min}$ before testing. Injection sites were confirmed histologically, as previously described (Trezza et al, 2011, 2012). Only pairs in which both animals had bilateral needle tracks terminating in the NAc without damage to the NAc were included in the final analysis.

\section{Social Play Behavior}

The experiments were performed in a sound-attenuated chamber under dim light conditions. The testing arena 
consisted of a Plexiglas cage measuring $40 \times 40 \times 60 \mathrm{~cm}$ $(1 \times w \times h)$. The behavior of the animals was recorded using a video camera with zoom lens, DVD recorder, and LCD monitor.

Social play behavior was assessed as previously described (Trezza et al, 2011, 2012). At 1 week after surgery, rats were habituated to the experimental procedures on 2 consecutive days. On the first habituation day, they were individually placed into the test cage for $10 \mathrm{~min}$, and on the second habituation day, they were isolated for $2 \mathrm{~h}$. Pairs of rats were then infused with a vehicle solution and placed into the test cage for $15 \mathrm{~min}$ to habituate them to the infusion procedures and to determine baseline levels of social play behavior. On the test day, the animals were isolated for $2 \mathrm{~h}$ before testing, unless otherwise indicated (see below). Pairs of rats were then infused simultaneously with either vehicle or drug solutions and placed into the test cage for $15 \mathrm{~min}$. Both animals in a test pair received the same treatment. Animals in a test pair did not differ by $>10 \mathrm{~g}$ in body weight and had no previous common social experience (ie, they were no cage mates). In three experiments (Figures $2 \mathrm{e}$ and $\mathrm{f}, 3 \mathrm{e}$ and $\mathrm{f}$, and $4 \mathrm{e}$ and $\mathrm{f}$ ), the animals were isolated for either $24 \mathrm{~h}$ or 7 days before testing, a time course that does not induce long-lasting behavioral disturbances in the social domain (Hol et al, 1999; Vanderschuren et al, 2008) but does induce maximal levels of social play behavior (Niesink and Van Ree, 1989; Vanderschuren et al, 1995a).

Behavior was assessed per pair of animals by a trained observer who was unaware of treatment conditions, using the Observer XT software (Noldus).

The following parameters were scored per pair of animals:

- Frequency of pinning: one animal lying with its dorsal surface on the floor with the other animal standing over it. This is the most characteristic posture in social play in rats, occurring when one animal is solicited to play by its test partner and rotates to its dorsal surface (Pellis and Pellis, 2009; Trezza et al, 2010);

- Frequency of pouncing: one animal is soliciting the other to play, by attempting to nose or rub the nape of the neck of the test partner (Pellis and Pellis, 2009; Trezza et al, 2010);

- Time spent on social exploration: sniffing or grooming any part of the body of the test partner, including the anogenital area.

In one experiment, locomotor activity of the animals was also scored as follows: a grid, dividing the test arena into 25 equally sized compartments, was projected over the social behavior recordings, and the number of line crossings was counted separately for each animal of a pair.

\section{Statistical Analysis}

Pinning and pouncing frequencies, time spent in social exploration, and line crossings were expressed as mean \pm SEM. To assess the effects of single or combined treatments and the effects of social isolation on social play behavior, data were analyzed using Student's $t$-test, one-way or two-way analysis of variance (ANOVA) followed by Student-Newman-Keuls post hoc tests where appropriate.

\section{RESULTS}

\section{Pharmacological Manipulation of NAc Dopaminergic Activity Affects Social Play Behavior}

To pinpoint the role of dopaminergic neurotransmission in the NAc in the modulation of social play, we tested the effects of intra-NAc infusions of the dopamine releaser/ reuptake inhibitor amphetamine, the nonselective dopamine receptor agonist apomorphine, and the selective dopamine reuptake inhibitor GBR-12909 on social play behavior.

Intra-NAc infusion of amphetamine increased social play (pinning: $\quad\left(\mathrm{F}_{(4,56)}=11.408, \quad p<0.001\right)$; pouncing: $\left.\left(F_{(4,56)}=10.492, p<0.001\right)\right)$. The post hoc analysis revealed that amphetamine, infused at the doses of 0.03 and $0.1 \mu \mathrm{g}$, increased pinning (Figure 1a) and pouncing (Figure 1b). The effects of amphetamine on social play were not secondary to changes in locomotor activity: indeed, at the doses that increased social play behavior $(0.03$ and $0.1 \mu \mathrm{g})$, amphetamine did not affect the number of crossings $\left(\left(\mathrm{F}_{(4,56)}=13.24\right.\right.$, $p<0.001$ ); post hoc analysis: $p=0.470$ for the dose of $0.03 \mu \mathrm{g}$ and $p=0.751$ for the dose of $0.1 \mu \mathrm{g} / 0.3 \mu \mathrm{l}$; data not shown).

Intra-NAc infusion of the nonselective dopamine receptor agonist apomorphine increased social play (pinning: $\left(\mathrm{F}_{(2,26)}=3.429, \quad p<0.05\right)$; $\quad$ pouncing: $\quad\left(\mathrm{F}_{(2,26)}=3.564\right.$, $p<0.05))$. The post hoc analysis revealed that apomorphine increased pinning at the dose of $0.1 \mu \mathrm{g}$ (Figure 1c), and increased pouncing at the doses of 0.01 and $0.1 \mu \mathrm{g}$ (Figure 1d). Conversely, intra-NAc infusion of the dopamine reuptake inhibitor GBR-12909 did not affect social play (pinning: $\left(\mathrm{F}_{(4,41)}=1.225, \quad p=0.312\right.$; $\quad$ Figure $\left.1 \mathrm{e}\right)$; pouncing: $\left(\mathrm{F}_{(4,41)}=1.861, p=0.119\right.$; Figure 1f) $)$.

We next investigated whether the increase in social play behavior induced by intra-NAc infusion of amphetamine depended on activation of dopamine receptors. Intra-NAc infusion of the nonselective dopamine receptor antagonist $\alpha$-flupenthixol prevented the play-enhancing effects of intra-NAc infusion of amphetamine (pinning: $\left(\mathrm{F}_{(\mathrm{AMPH}) 1,37}=4.433, p<0.01 ; \mathrm{F}_{(\mathrm{FLUP}) 1,37}=7.937, p<0.05\right.$; $\mathrm{F}_{(\mathrm{AMPH} \times \mathrm{FLUP}) 1,37}=6.817, p<0.05 ;$ Figure $\left.2 \mathrm{a}\right)$; pouncing: $\left(\mathrm{F}_{(\mathrm{AMPH}) 1,37}=5.876, p<0.05 ; \mathrm{F}_{(\mathrm{FLUP}) 1,37}=12.13, p<0.01\right.$; $\mathrm{F}_{(\mathrm{AMPH} \times \text { FLUP }) 1,37}=4.272, p<0.05$; Figure $\left.\left.2 \mathrm{~b}\right)\right)$. The post hoc analysis revealed that intra-NAc amphetamine increased social play when coinfused with vehicle but not when coinfused with $\alpha$-flupenthixol, whereas flupenthixol did not alter social play behavior by itself. These data indicate that the increase in social play behavior induced by intra-NAc infusion of amphetamine is mediated by activation of NAc dopamine receptors. As systemic treatment with higher doses of $\alpha$-flupenthixol reduces social play behavior (Trezza and Vanderschuren, 2009), we therefore reasoned that blockade of NAc dopamine receptors by intra-NAc infusion of a higher dose of $\alpha$-flupenthixol would reduce social play behavior. However, contrary to our expectation, intra-NAc infusion of $\alpha$-flupenthixol did not affect social play behavior (pinning: $\left(\mathrm{F}_{(3,46)}=0.570, p=0.685\right.$; Figure $2 \mathrm{c}$ ); pouncing $\left(\mathrm{F}_{(3,46)}=3.232, p=0.128\right.$; Figure $\left.\left.2 \mathrm{~d}\right)\right)$.

The rats used in these experiments were isolated for $2 \mathrm{~h}$ before testing. A close relationship exists between the length of social isolation and the amount of social play behavior expressed during testing (Niesink and Van Ree, 1989; Vanderschuren et al, 1995a). Indeed, we have recently shown 

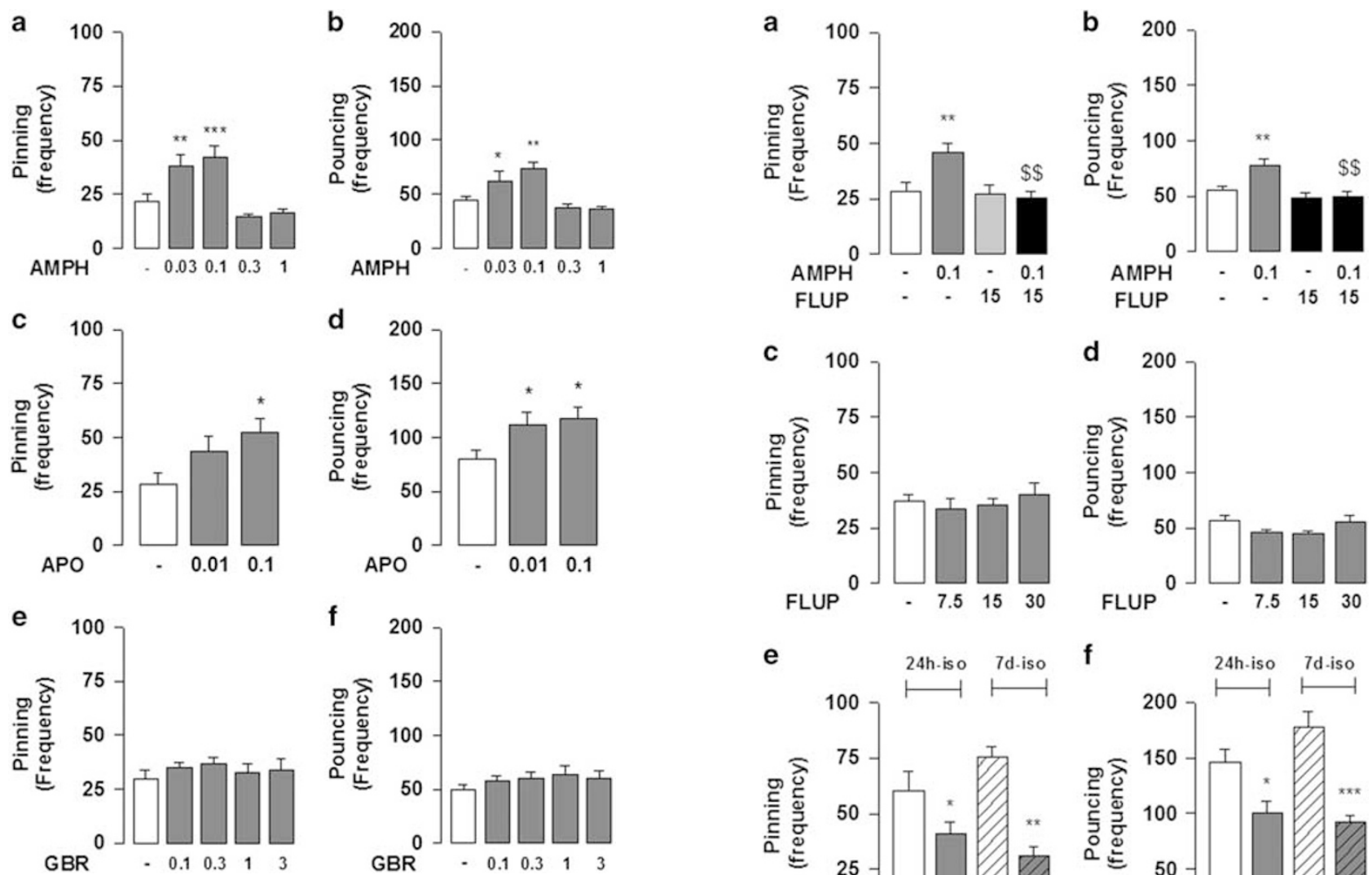

Figure I Manipulation of NAc dopaminergic neurotransmission affects social play behavior. Intra-NAc infusion of the dopamine releaser/uptake inhibitor amphetamine (AMPH: 0.03 and $0.1 \mu g / 0.3 \mu l)$ increased pinning (a) and pouncing (b). Similarly, intra-NAc infusion of the nonselective dopamine receptor agonist apomorphine (APO: $0.1 \mu g / 0.3 \mu l$ ) increased social play behavior ( $c, d)$. Intra-NAc infusion of the selective dopamine reuptake inhibitor GBR-12909 (GBR) did not affect social play behavior (e, f). Data represent mean \pm SEM pinning $(a, c, e)$ and pouncing $(b, d, f)$ frequency. $* P<0.05$, $* * p<0.01$, $* * * * 0<0.00$ I vs vehicle treatment (Student-Newman-Keuls post hoc test). $N=8-14$ per group.

that animals isolated for $24 \mathrm{~h}$ show a higher motivation for social play behavior in an operant conditioning task than animals isolated for $2 \mathrm{~h}$ (Achterberg et al, 2016). As incentive motivation, including motivation for social play (Achterberg et al, 2016), depends on dopaminergic neurotransmission (Kelley, 2004; Barbano and Cador, 2007; Berridge, 2007; Salamone and Correa, 2012), we hypothesized that animals highly motivated for social play behavior as a result of longer social isolation before testing would be more sensitive to blockade of NAc dopamine receptors. To test this hypothesis, we investigated the effects of intra-NAc infusion of $\alpha$ flupenthixol in animals socially isolated for either $24 \mathrm{~h}$ or 7 days before testing. As expected, after $24 \mathrm{~h}$ and 7 days of social isolation, vehicle-treated rats showed levels of social play behavior about twice higher compared with those observed after $2 \mathrm{~h}$ of isolation (pinning: $24 v s 2 \mathrm{~h}$ of isolation: $t_{16}=4.435, p<0.001 ; 7$ days $v s 2 \mathrm{~h}$ of isolation: $t_{18}=6.006$, $p<0.0001$; pouncing: $24 v s 2 \mathrm{~h}$ of isolation: $t_{16}=9.119$, $p<0.0001 ; 7$ days $v s 2 \mathrm{~h}$ of isolation: $t_{18}=9.596, p<0.0001$; data not shown). A two-way ANOVA analysis performed on the behavioral parameters measured in animals treated with either vehicle or $\alpha$-flupenthixol and isolated for either $24 \mathrm{~h}$ or 7 days gave the following results: pinning
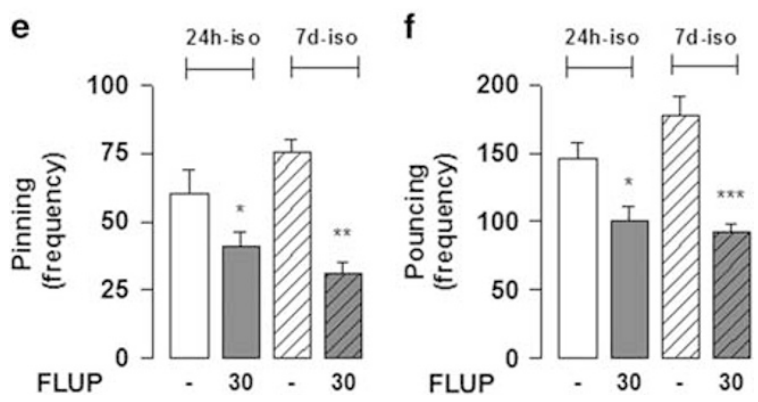

Figure 2 The nonselective dopamine receptor antagonist $\alpha$-flupenthixol blocked the play-enhancing effects of intra-NAc infusion of amphetamine and reduced social play in highly motivated rats. Coinfusion with a noneffective dose of $\alpha$-flupenthixol (FLUP; $\mid 5 \mu \mathrm{g} / 0.3 \mu \mathrm{l}$ ) antagonized the increase in pinning (a) and pouncing (b) induced by intra-NAc infusion of amphetamine (AMPH; $0.1 \mu g / 0.3 \mu \mathrm{l})$. Dose-response experiments showed that intra-NAc infusion of $\alpha$-flupenthixol did not affect social play behavior (c, d). However, intra-NAc infusion of $\alpha$-flupenthixol decreased pinning (e) and pouncing $(f)$ in animals isolated for either $24 \mathrm{~h}$ or 7 days before testing. Data represent mean \pm SEM frequency of pinning $(a, c, e)$ and pouncing (b, d, f). $* P<0.05$, *** $p<0.0$ I, ${ }^{*} * * * 0.00$ I vs vehicle treatment; ${ }^{\$ \$} p<0.0$ I vs vehicle/AMPH (Student-Newman-Keuls post hoc test). $N=8-14$ per group.

$\left(\mathrm{F}_{\text {(isolation)1,31 }}=0.189, \quad p=0.666 ; \quad \mathrm{F}_{\text {(treatment)1,31 }}=28.400\right.$, $p<0.0001 ; \quad \mathrm{F}_{\text {(isolation } \times \text { treatment) } 1,31}=4.163, \quad p<0.05$; Figure 2e); pouncing $\left(\mathrm{F}_{(\text {isolation }) 1,31}=1.067, \quad p=0.309\right.$; $\mathrm{F}_{\text {(treatment)1,31 }}=24.376, \quad p<0.0001 ; \quad \mathrm{F}_{\text {(isolation } \times \text { treatment)1, 31 }}=$ 3.061, $p=0.090$; Figure 2f). The post hoc analysis revealed that intra-NAc infusion of $\alpha$-flupenthixol decreased social play in animals isolated for either $24 \mathrm{~h}$ or 7 days before testing.

\section{Role of NAc D1 and D2 Dopamine Receptors in Social Play Behavior}

To investigate the relative contribution of NAc D1 and D2 dopamine receptors in social play, we tested whether blockade of these receptors by selective dopamine receptor antagonists counteracted the play-enhancing effects of intraNAc infusion of amphetamine. The play-enhancing effects of 
intra-NAc amphetamine infusion were prevented by coinfusion with the D1 dopamine receptor antagonist SCH-23390 (pinning: $\left(\mathrm{F}_{(\mathrm{AMPH}) 1,31}=8.253, p<0.01 ; \mathrm{F}_{(\mathrm{SCH}) 1,31}=2.255\right.$, $p=0.143 ; \quad \mathrm{F}_{(\mathrm{AMPH} \times \mathrm{SCH}) 1,31}=4.429, \quad p<0.05 ;$ Figure 3a); pouncing: $\left(\mathrm{F}_{(\mathrm{AMPH}) 1,31}=8.870, p<0.01 ; \mathrm{F}_{(\mathrm{SCH}) 1,31}=3.122\right.$, $p=0.087 ; \mathrm{F}_{(\mathrm{AMPH} \times \mathrm{SCH}) 1,31}=4.414, p<0.05$; Figure $\left.\left.3 \mathrm{~b}\right)\right)$. The post hoc analysis revealed that intra-NAc infusion of SCH-23390, at a dose that had no effects by itself, antagonized the increase in social play induced by intraNAc infusion of amphetamine. Similar to $\alpha$-flupenthixol, however, intra-NAc infusion of higher doses of SCH-23390 did not affect social play behavior in animals briefly isolated before testing (pinning: $\left(\mathrm{F}_{(3,35)}=0.784, p=0.511\right.$; Figure $3 \mathrm{c}$ ); pouncing $\left(\mathrm{F}_{(3,35)}=3.262, p<0.05\right.$; Figure $\left.\left.3 \mathrm{~d}\right)\right)$. The post hoc analysis revealed that, at the highest dose tested, $\mathrm{SCH}-23390$ only reduced the frequency of pouncing (Figure 3d). Conversely, intra-NAc infusion of SCH-23390 suppressed social play in animals isolated for either $24 \mathrm{~h}$ or 7 days before testing (pinning: $\left(\mathrm{F}_{\text {(isolation)1, 24 }}=0.396, p=0.535 ; \mathrm{F}_{\text {(treatment)1, } 24}\right.$ $=12.53, \quad p<0.01 ; \quad \mathrm{F}_{\text {(isolation } \times \text { treatment) } 1,24}=0.251, \quad p=0.987$; Figure 3e); pouncing: $\quad\left(\mathrm{F}_{\text {(isolation)1, 24 }}=0.641, \quad p=0.431\right.$; $\mathrm{F}_{\text {(treatment)1, 24 }}=33.02, \quad p<0.0001 ; \quad \mathrm{F}_{\text {(isolation } \times \text { treatment)1, } 24}$ $=0.019, p=0.890$; Figure $3 \mathrm{f})$ ).

The play-enhancing effects of intra-NAc amphetamine were also prevented by coinfusion of the D2 dopamine receptor antagonist eticlopride (pinning: $\left(\mathrm{F}_{(\mathrm{AMPH}) 1,27}=\right.$ 5.704, $p<0.05 ; \mathrm{F}_{(\mathrm{ETICL}) 1,27}=2.70, p=0.112 ; \mathrm{F}_{(\mathrm{AMPH} \times \mathrm{ETICL}) 1,27}$ $=4.327, p<0.05$; Figure $4 \mathrm{a})$; pouncing: $\left(\mathrm{F}_{(\mathrm{AMPH}) 1,27}=3.195\right.$, $p=0.085 ; \quad \mathrm{F}_{(\mathrm{ETTCL}) 1,27}=4.175, \quad p=0.051 ; \quad \mathrm{F}_{(\mathrm{AMPH} \times \mathrm{ETICL}) 1,27}$ $=4.211, p<0.05$; Figure $4 \mathrm{~b})$ ). The post hoc analysis revealed that intra-NAc infusion of eticlopride, at a dose that itself did not affect social play $(10 \mu \mathrm{g})$, antagonized the increase in social play induced by intra-NAc infusion of amphetamine. Intra-NAc infusion of eticlopride did not affect social play behavior in animals briefly isolated before testing (pinning: $\left(\mathrm{F}_{(4,50)}=1.802, \quad p=0.143 ; \quad\right.$ Figure $\left.4 \mathrm{c}\right) ; \quad$ pouncing: $\left(\mathrm{F}_{(4,50)}=3.268, p<0.05\right.$; Figure $\left.\left.4 \mathrm{~d}\right)\right)$. However, eticlopride $(15 \mu \mathrm{g})$ reduced social play in animals highly motivated to play as a result of social isolation for either $24 \mathrm{~h}$ or 7 days before testing (pinning: $\left(\mathrm{F}_{\text {(isolation)1, 32 }}=2.868, p=0.100 ; \mathrm{F}_{\text {(treatment)1, } 32}\right.$ $=28.104, p<0.001 ; \quad F_{\text {(isolation } \times \text { treatment) } 1,32}=2.876, p=0.100$; Figure 4e); pouncing: $\quad\left(\mathrm{F}_{\text {(isolation)1, 32 }}=4.505, \quad p<0.05\right.$; $\mathrm{F}_{\text {(treatment)1, 32 }}=19.032, p<0.001 ; \mathrm{F}_{\text {(isolation } \times \text { treatment)1, 32 }}=0.773$, $p=0.386$; Figure 4f)). Together, these data indicate that both D1 and D2 dopamine receptors in the NAc modulate social play behavior, particularly under high motivational conditions induced by social isolation.

\section{Activation of Dopamine Receptors in the NAc Is Necessary and Sufficient for Endocannabinoid and Opioid Modulation of Social Play Behavior}

To investigate the contribution of NAc dopaminergic neurotransmission in endocannabinoid- and opioidmediated increase in social play behavior (Trezza and Vanderschuren, 2008), we tested whether blockade of NAc dopamine receptors by $\alpha$-flupenthixol antagonized the play-enhancing effects of systemic administration of either the anandamide hydrolysis inhibitor URB597 $(0.1 \mathrm{mg} / \mathrm{kg})$ (Trezza and Vanderschuren, 2008) or the opioid receptor agonist morphine $(1 \mathrm{mg} / \mathrm{kg})$ (Vanderschuren et al, 1995a).
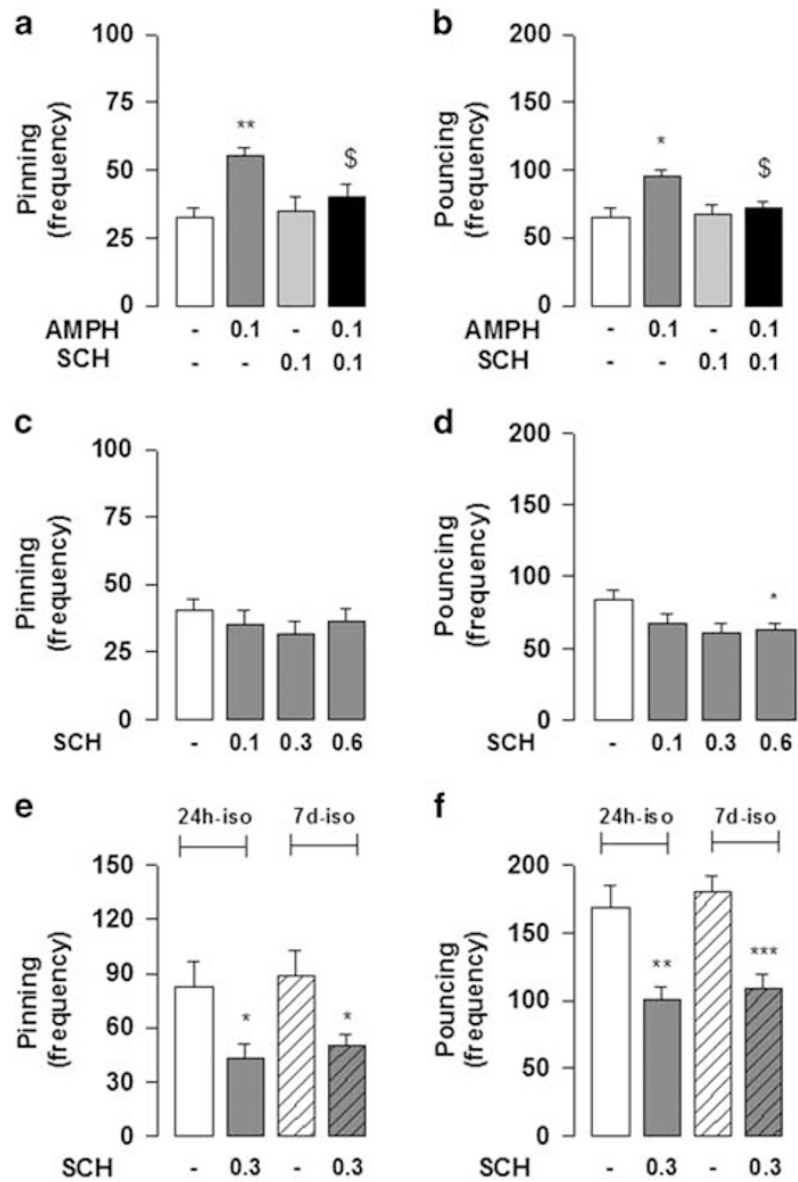

Figure 3 Contribution of NAc DI dopamine receptors in social play. Intra-NAc infusion of the DI dopamine receptor antagonist SCH-23390 $(\mathrm{SCH}: 0.1 \mu \mathrm{g} / 0.3 \mu \mathrm{l})$ attenuated the increase in pinning (a) and pouncing (b) induced by intra-NAc infusion of amphetamine (AMPH; $0.1 \mu \mathrm{g} / 0.3 \mu \mathrm{l})$. At the highest dose tested $(0.6 \mu \mathrm{g} / 0.3 \mu \mathrm{l})$, intra-NAc infusion SCH-23390 only reduced pouncing (d) without affecting pinning (c). Conversely, intra-NAc infusion of SCH-23390 (0.3 $\mu \mathrm{g} / 0.3 \mu \mathrm{l})$ decreased pinning (e) and pouncing ( $\mathrm{f})$ in animals socially isolated for $24 \mathrm{~h}$ or 7 days before testing. Data represent mean \pm SEM frequency of pinning $(a, c, e)$ and pouncing $(b, d, f)$. $* P<0.05$, $*^{*}{ }^{2}<0.01, * * * * 0.001$ vs vehicle treatment; ${ }^{\$} p<0.05$ vs vehicle/AMPH (Student-Newman-Keuls post hoc test). $N=6-14$ per group.

Intra-NAc infusion of $\alpha$-flupenthixol antagonized the effects of systemic URB597 treatment on social play (pinning: $\left(\mathrm{F}_{(\mathrm{URB} 597) 1,37}=3.801, p=0.058 ; \mathrm{F}_{(\mathrm{FLUP}) 1,37}=4.736, p<0.05\right.$; $\mathrm{F}_{(\mathrm{URB} \times \mathrm{FLUP}) 1,37}=9.612, \quad p<0.01$; Figure $\left.5 \mathrm{a}\right)$; pouncing: $\left(\mathrm{F}_{\text {(URB } 597) 1,37}=10.374, \quad p<0.01 ; \quad \mathrm{F}_{(\mathrm{FLUP}) 1,37}=17.531\right.$, $p<0.01 ; \mathrm{F}_{(\mathrm{URB} \times \mathrm{FLUP}) 1,37}=11.035, p<0.01$; Figure $\left.5 \mathrm{~b}\right)$ ). The post hoc analysis showed that URB597 increased social play in rats that received intra-NAc vehicle but not in animals that received intra-NAc $\alpha$-flupenthixol.

Similarly, intra-NAc infusion of $\alpha$-flupenthixol antagonized the increase in social play induced by systemic morphine treatment (pinning: $\left(\mathrm{F}_{(\mathrm{MOR}) 1,19}=9.595, p<0.01 ; \mathrm{F}_{(\mathrm{FLUP}) 1,19}=\right.$ 8.744, $p<0.01 ; \mathrm{F}_{(\mathrm{MOR} \times \mathrm{FLUP}) 1,19}=4.796, p<0.05$; Figure $\left.5 \mathrm{c}\right)$; pouncing: $\left(\mathrm{F}_{(\mathrm{MOR}) 1,19}=20.038, p<0.001 ; \mathrm{F}_{(\mathrm{FLUP}) 1,19}=16.586\right.$, $p<0.001 ; \mathrm{F}_{(\mathrm{MOR} \times \mathrm{FLUP}) 1,19}=12.396, p<0.01 ;$ Figure $\left.5 \mathrm{~d}\right)$ ). The post hoc analysis showed that morphine increased social play in rats that received intra-NAc vehicle but not in animals that received intra-NAc $\alpha$-flupenthixol. Together, these results show that dopaminergic neurotransmission in 

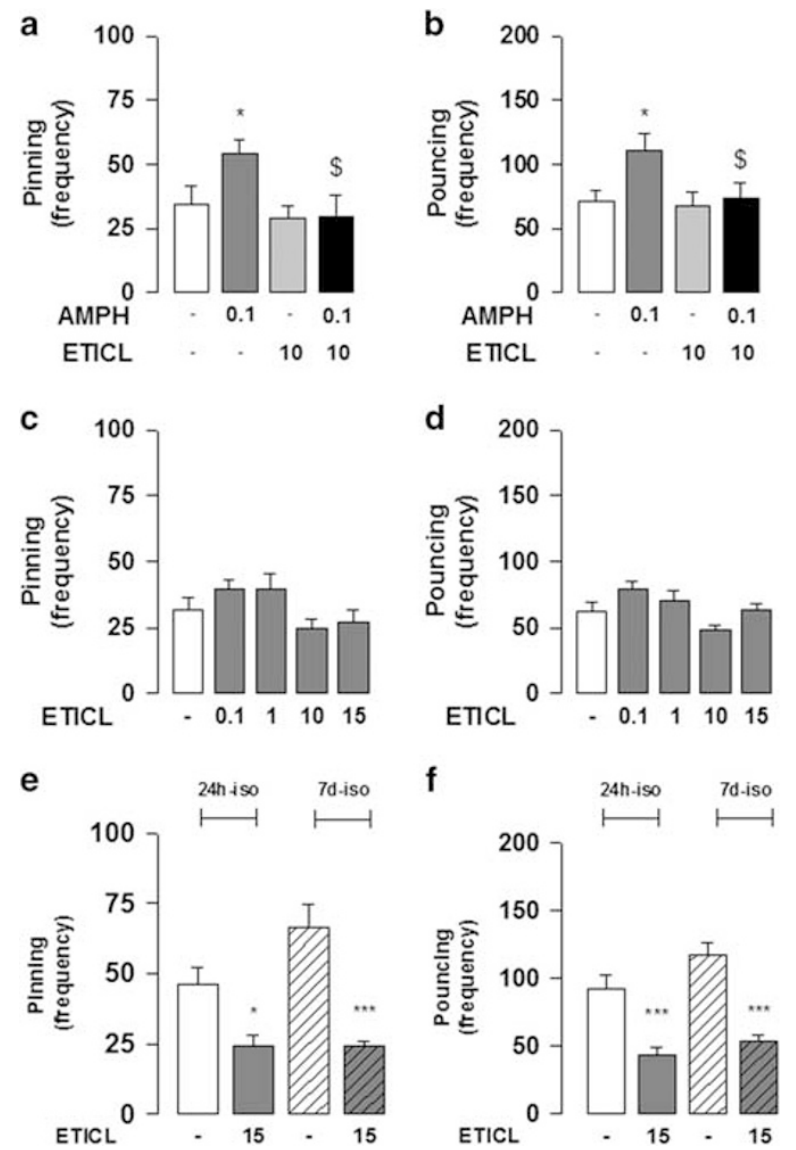

Figure 4 Contribution of NAc D2 dopamine receptors in social play. Intra-NAc infusion of the dopamine D2 receptor antagonist eticlopride $(\mathrm{ETICL}: 10 \mu \mathrm{g} / 0.3 \mu \mathrm{l})$ blocked the increase in pinning (a) and pouncing (b) induced by intra-NAc infusion of amphetamine (AMPH; $0.1 \mu g / 0.3 \mu l)$. IntraNAc infusion of graded doses of eticlopride did not affect social play behavior in animals briefly isolated before testing (c, d). However eticlopride decreased pinning (e) and pouncing (f) in animals socially isolated for $24 \mathrm{~h}$ or 7 days before testing. Data represent mean \pm SEM frequency of pinning $(a, c, e)$ and pouncing ( $b, d, f)$. $* P<0.05$, **** $p<0.00$ I vs vehicle treatment; $\$_{p}<0.05$ vs vehicle/AMPH (Student-Newman-Keuls post hoc test). $N=6-15$ per group.

the NAc underlies the play-enhancing effects of opioids and endocannabinoids.

In all the experiments showed in Figures 1, 2, 3, 4 and 5, pharmacological manipulations did not affect general social exploration (ie, sniffing and grooming any part of the body of the test partner, including the anogenital area) (Supplementary Table S1).

For histological assessment of representative experiments see Supplementary Figure S1.

\section{DISCUSSION}

The mesolimbic dopaminergic system is critically involved in the processing of food, sex, and drug rewards (Kelley, 2004; Berridge and Kringelbach, 2008; Everitt and Robbins, 2005; Salamone and Correa, 2012; Volkow and Morales, 2015). However, less information is available about the role of mesolimbic dopamine in the modulation of rewarding social interactions other than sex, particularly at young age. This
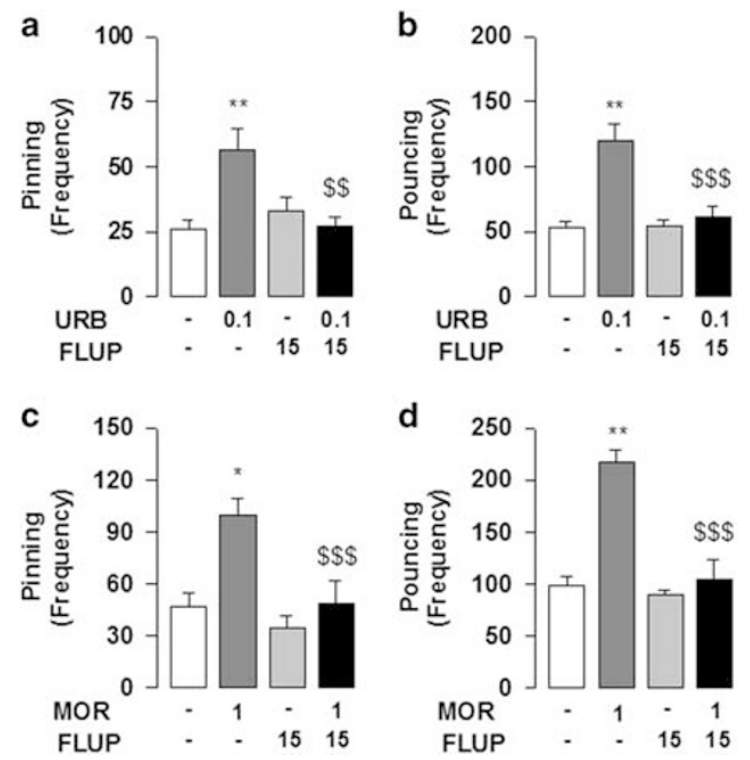

Figure 5 Activation of dopamine receptors in the NAc is necessary for endocannabinoid and opioid modulation of social play behavior. Systemic administration of URB597 (URB; 0.1 mg/ $/ \mathrm{kg}$, i.p.) increased pinning (a) and pouncing (b) in rats that received intra-NAc vehicle but not in animals that received intra-NAc $\alpha$-flupenthixol (FLUP; I $5 \mu g / 0.3 \mu \mathrm{l}$ ). Similarly, intra-NAc infusion of $\alpha$-flupenthixol antagonized the increase in social play (c, d) induced by systemic morphine treatment (MOR; I mg/kg, s.c.). Data represent mean \pm SEM frequency of pinning $(a, c)$ and pouncing $(b, d)$. $* P<0.05, \quad * * * 0.01$ vs vehicle treatment; ${ }^{\$ \$} p<0.0$ I, ${ }^{\$ \$ \$} p<0.00$ I vs vehicle/AMPH and vehicle/MOR (Student-Newman-Keuls post hoc test). $N=5-$ I I per group.

knowledge is of great relevance for our understanding of the neural circuits that underlie adaptive social development, as well as the pathophysiology of developmental psychiatric diseases characterized by social dysfunctions (Alessandri, 1992; Jordan, 2003). Here, we provide evidence for an important role of NAc dopaminergic neurotransmission in the modulation of social play behavior that is the most characteristic, rewarding form of social interaction displayed by young mammals (Panksepp et al, 1984; Pellis and Pellis, 2009; Trezza et al, 2010).

We found that increasing extracellular NAc dopamine concentrations by infusion of low doses of the dopamine releaser/reuptake inhibitor amphetamine increased social play behavior. This effect was behaviorally specific, as at the doses that increased social play, intra-NAc infusion of amphetamine did not affect social exploratory behavior or locomotor activity during the social encounter. The playenhancing effects of intra-NAc infusion of amphetamine were mimicked by intra-NAc infusion of the dopamine receptor agonist apomorphine, but not by infusion of the dopamine reuptake inhibitor GBR-12909. These results suggest that direct activation of dopamine receptors in the NAc, either by amphetamine-induced exocytotic dopamine release (Daberkow et al, 2013) or by apomorphine binding, is necessary to positively affect social play behavior in rats. Conversely, prolonging ongoing NAc dopaminergic tone by inhibiting dopamine uptake is insufficient. This interpretation is supported by data showing that intra-NAc infusion of the dopamine/noradrenaline reuptake inhibitor methylphenidate does not affect social play behavior (Achterberg et al, 
2015). Similarly, systemic administration of GBR-12909 increased operant responding for social play (Achterberg et al, 2016), but did not affect the expression of social play behavior (Achterberg et al, 2016; Vanderschuren et al, 2008).

The play-enhancing effects of intra-NAc infusion of amphetamine depended upon stimulation of dopamine receptors, as they were antagonized by the nonselective dopamine receptor antagonist $\alpha$-flupenthixol, infused into the NAc at a dose that had no effects on social play by itself. Interestingly, intra-NAc infusion of higher doses of $\alpha$ flupenthixol also did not affect social play. We have recently shown that blockade of dopaminergic neurotransmission by systemic administration of $\alpha$-flupenthixol reduces motivation for social play in a lever pressing task, without altering the performance of social play during reinforced periods (Achterberg et al, 2016), although systemic treatment with higher doses of $\alpha$-flupenthixol does reduce social play behavior (Trezza and Vanderschuren, 2009). It has been shown that long periods of social isolation after weaning affect mesolimbic dopaminergic activity (Yorgason et al, 2013, 2016; Whitaker et al, 2013). Thus, in line with the view that NAc dopaminergic neurotransmission plays a critical role in incentive motivation (Barbano and Cador, 2007; Kelley, 2004; Salamone and Correa, 2012), we hypothesized that animals highly motivated for social play as a result of longer social isolation before testing would be more sensitive to blockade of NAc dopamine receptors. Indeed, we found that after $24 \mathrm{~h}$ or 7 days of social isolation before testing, blockade of NAc dopaminergic neurotransmission by infusion of $\alpha$-flupenthixol decreased social play.

Neurons in the NAc are mostly GABAergic medium spiny output neurons (MSNs) expressing either D1 or D2 dopamine receptors (Voorn et al, 2004; Gerfen and Surmeier, 2011). These two subpopulations of NAc MSNs have been implicated in reward processes (Volkow and Morales, 2015), including those associated with affiliative behaviors (Young and Wang, 2004), although their precise roles in emotion-driven behavior are a matter of debate (Gerfen and Surmeier, 2011; Volkow and Morales, 2015). To investigate the relative contribution of NAc D1 or D2 dopamine receptors in social play, we tested whether blockade of these receptors using selective dopamine receptor antagonists counteracted the play-enhancing effects of intra-NAc infusion of amphetamine. We found that the play-enhancing effects of intra-NAc amphetamine were prevented by coinfusion with a noneffective dose of either the D1 dopamine receptor antagonist SCH-23390 or the D2 dopamine receptor antagonist eticlopride. Similar to $\alpha$ flupenthixol, intra-NAc infusion of SCH-23390 or eticlopride did not affect social play in animals briefly isolated before testing, but both drugs did reduce social play when infused in the NAc of animals isolated for either $24 \mathrm{~h}$ or 7 days before testing. Collectively, these results show that both D1 and D2 dopamine receptors in the NAc modulate social play behavior, particularly in animals highly motivated to the social interaction. The finding that (the drug-induced enhancement of) social play could be decreased by blockade of either D1 or D2 dopamine receptors indicates that optimal stimulation of both types of dopamine receptors is necessary for proper expression of social play behavior. This is consistent with a model in which the modulation of behavior by striatal dopamine requires the simultaneous stimulation of dopamine D1 and D2 receptors, whereby dopamine alters the activity of the direct and indirect striatal output pathways in concert (Gerfen and Surmeier 2011; Volkow and Morales, 2015).

The NAc is typically subdivided into a core and a shell subregion that are functionally and anatomically distinct (Cardinal et al, 2002; Voorn et al, 2004; Floresco, 2015). Our previous functional anatomical and pharmacological inactivation studies (van Kerkhof et al, 2013, 2014) suggested that these subregions are differentially involved in social play behavior. However, with regard to the modulation of social play by local opioid and cannabinoid signaling, there does not seem to be a major difference between the NAc core and shell (Trezza et al, 2011, 2012). Consistent with these latter findings, our pilot studies showed that infusion of amphetamine into both NAc core and shell stimulates social play behavior (Supplementary Figure S2), suggesting that dopamine activity throughout the NAc is involved in social play. Therefore, we targeted our infusions on the core/shell border (Supplementary Figure S1). Clearly, this does not rule out the possibility that the dopaminergic innervation of the NAc core $v s$ shell modulates different aspects of social play that, when stimulated, emerge as an increase in this behavior. This will be addressed in future studies.

Both endogenous opioids (Trezza et al, 2011) and endocannabinoids (Trezza et al, 2012) in the NAc modulate social play. Close interactions between dopaminergic, endocannabinoid, and endogenous opioid systems exist (Gardner, 2005; van Ree et al, 1999), including a functional interplay between these neurotransmitter systems in affective responses and social behaviors (Loureiro et al, 2015; Rodriguez-Arias et al, 1999; van Furth et al, 1995). We have previously shown that systemic administration of $\alpha$-flupenthixol antagonized the play-enhancing effects of systemic administration of URB597, but not morphine (Trezza and Vanderschuren, 2008). These results led us to hypothesize that endocannabinoids and endogenous opioids enhance social play through dopamine-dependent and dopamine-independent mechanisms, respectively (Trezza and Vanderschuren, 2008). This study, however, had two limitations. First, $\alpha$-flupenthixol was administered systemically, providing no information on the specific brain area underlying the interaction between dopamine and the endocannabinoid and opioid systems in social play. Second, the possibility that higher doses of $\alpha$-flupenthixol counteracted the opioid-induced increase in social play could not be tested, because systemic administration of higher doses of $\alpha$ flupenthixol suppresses social play and locomotor activity by itself (Trezza and Vanderschuren, 2009).

Dopaminergic neurotransmission in the NAc has been implicated in cannabinoid and opioid modulation of food and drug reward (Gardner, 2005; van Ree et al, 1999; Pierce and Kumaresan, 2006), although nondopaminergic forms of opioid and cannabinoid reward have also been described (van Ree et al, 1999; Pierce and Kumaresan, 2006). Therefore, in the last part of this study we investigated whether NAc dopaminergic neurotransmission underlies endocannabinoid and opioid-mediated increases in social play reward. To this aim, we tested whether intra-NAc infusion of $\alpha$ flupenthixol antagonized the play-enhancing effects induced by systemic administration of either the anandamide hydrolysis inhibitor URB597 (Trezza and Vanderschuren, 2008) or the opioid agonist morphine (Vanderschuren et al, 1995a). We found that systemic administration of either 
URB597 or morphine increased social play in rats that received intra-NAc vehicle but not in animals that received intra-NAc $\alpha$-flupenthixol. These results extend our previous findings (Trezza and Vanderschuren, 2008) and show that dopaminergic neurotransmission in the NAc closely interacts with the endocannabinoid and opioid systems in the modulation of social play behavior. The mostly likely underlying mechanism is the well-known disinhibition of ventral tegmental area dopamine neurons projecting to the NAc as a result of opioid receptor stimulation (Johnson and North, 1992; Jalabert et al, 2011). Similarly, endocannabinoid indirectly modulate ventral tegmental dopamine neuron activity by altering the functional activity of the GABA and glutamate inputs received by dopaminergic neurons (Gardner, 2005), even though a direct regulation of dopamine function by certain cannabinoids has been found in some dopaminergic pathways (Fernández-Ruiz et al, 2010).

Collectively, our results show that dopaminergic neurotransmission in the NAc has a critical role in social play behavior in rats. These findings resonate well with other studies in laboratory animals reporting increased activity in the mesolimbic dopaminergic system upon social interactions (Gunaydin and Deisseroth, 2014; Robinson et al, 2002, 2011) and with genetic studies in humans showing an important role for striatal dopamine in processing appetitive socially relevant stimuli (Eisenegger et al, 2013; Enter et al, 2012). Thus, functional activity in the mesolimbic dopamine pathway has an important modulatory role in adaptive social behavior. Conversely, abnormalities in NAc dopamine signaling may be associated with deficits in social reward processing (Bowton et al, 2014; Hettinger et al, 2008) and may have a causal role in the impairments in social play behavior observed in developmental psychiatric disorders such as autism or early-onset schizophrenia.

\section{FUNDING AND DISCLOSURE}

The authors declare no conflict of interest.

\section{ACKNOWLEDGMENTS}

This study was supported by the Netherlands Organization for Scientific Research (NWO) Veni grant 91611052 (to VT), Marie Curie Career Reintegration grant PCIG09-GA-2011293589 (to VT), and the National Institute on Drug Abuse grant R01 DA022628 (to LJMJV), The Netherlands.

\section{REFERENCES}

Achterberg EJM, Trezza V, Siviy SM, Schrama L, Schoffelmeer ANM, Vanderschuren LJMJ (2014). Amphetamine and cocaine suppress social play behavior in rats through distinct mechanisms. Psychopharmacology 231: 1503-1515.

Achterberg EJM, van Kerkhof LW, Damsteegt R, Trezza V, Vanderschuren LJMJ (2015). Methylphenidate and atomoxetine inhibit social play behavior through prefrontal and subcortical limbic mechanisms in rats. J Neurosci 35: 161-169.

Achterberg EJM, van Kerkhof LW, Servadio M, van Swieten MM, Houwing DJ, Aalderink $M$ et al (2016). Contrasting roles of dopamine and noradrenaline in the motivational properties of social play behavior in rats. Neuropsychopharmacology 41: 858-868.
Alessandri SM (1992). Attention, play, and social behavior in ADHD preschoolers. J Abnorm Child Psychol 20: 289-302.

Barbano MF, Cador M (2007). Opioids for hedonic experience and dopamine to get ready for it. Psychopharmacology (Berl) 191: 497-506.

Beatty WW, Costello KB, Berry SL (1984). Suppression of play fighting by amphetamine: effects of catecholamine antagonists, agonists and synthesis inhibitors. Pharmacol Biochem Behav 20: 747-755.

Berridge KC (2007). The debate over dopamine's role in reward: the case for incentive salience. Psychopharmacology (Berl) 191: 391-431.

Berridge KC, Kringelbach ML (2008). Affective neuroscience of pleasure: reward in humans and animals. Psychopharmacology (Berl) 199: 457-480.

Bowton E, Saunders C, Reddy IA, Campbell NG, Hamilton PJ, Henry LK et al (2014). SLC6A3 coding variant Ala559Val found in two autism probands alters dopamine transporter function and trafficking. Transl Psychiatry 4: e464.

Calcagnetti DJ, Schechter MD (1992). Place conditioning reveals the rewarding aspect of social interaction in juvenile rats. Physiol Behav 51: 667-672.

Cardinal RN, Parkinson JA, Hall J, Everitt BJ (2002). Emotion and motivation: the role of the amygdala, ventral striatum, and prefrontal cortex. Neurosci Biobehav Rev 26: 321-352.

Daberkow DP, Brown HD, Bunner KD, Kraniotis SA, Doellman MA, Ragozzino ME et al (2013). Amphetamine paradoxically augments exocytotic dopamine release and phasic dopamine signals. J Neurosci 33: 452-463.

Eisenegger C, Pedroni A, Rieskamp J, Zehnder C, Ebstein R, Fehr E et al (2013). DAT1 polymorphism determines L-DOPA effects on learning about others' prosociality. PLoS One 8: e67820.

Enter D, Colzato LS, Roelofs K (2012). Dopamine transporter polymorphisms affect social approach-avoidance tendencies. Genes Brain Behav 11: 671-676.

Everitt BJ, Robbins TW (2005). Neural systems of reinforcement for drug addiction: from actions to habits to compulsion. Nat Neurosci 8: 1481-1489.

Falk JL (1958). The grooming behavior of the chimpanzee as a reinforcer. J Exp Anal Behav 1: 83-85.

Fernández-Ruiz J, Hernández M, Ramos JA (2010). Cannabinoiddopamine interaction in the pathophysiology and treatment of CNS disorders. CNS Neurosci Ther 16: e72-e91.

Floresco SB (2015). The nucleus accumbens: an interface between cognition, emotion, and action. Annu Rev Psychol 66: 25-52.

Gardner EL (2005). Endocannabinoid signaling system and brain reward: emphasis on dopamine. Pharmacol Biochem Behav 81: 263-284.

Gerfen CR, Surmeier DJ (2011). Modulation of striatal projection systems by dopamine. Annu Rev Neurosci 34: 441-466.

Gordon NS, Kollack-Walker S, Akil H, Panksepp J (2002). Expression of c-fos gene activation during rough and tumble play in juvenile rats. Brain Res Bull 57: 651-659.

Gunaydin LA, Deisseroth K (2014). Dopaminergic dynamics contributing to social behavior. Cold Spring Harb Symp Quant Biol 79: 221-227.

Hettinger JA, Liu X, Schwartz CE, Michaelis RC, Holden JJ (2008). A DRD1 haplotype is associated with risk for autism spectrum disorders in male-only affected sib-pair families. Am J Med Genet B Neuropsychiatr Genet 147B: 628-636.

Hol T, Van den Berg CL, Van Ree JM, Spruijt BM (1999). Isolation during the play period in infancy decreases adult social interactions in rats. Behav Brain Res 100: 91-97.

Ikemoto S, Panksepp J (1992). The effects of early social isolation on the motivation for social play in juvenile rats. Dev Psychobiol 25: 261-274.

Jalabert M, Bourdy R, Courtin J, Veinante P, Manzoni OJ, Barrot M et al (2011). Neuronal circuits underlying acute morphine action on dopamine neurons. Proc Natl Acad Sci USA 108: 16446-16450. 
Johnson SW, North RA (1992). Opioids excite dopamine neurons by hyperpolarization of local interneurons. J Neurosci 12: 483-488.

Jordan R (2003). Social play and autistic spectrum disorders: a perspective on theory, implications and educational approaches. Autism 7: 347-360.

Keiflin R, Janak PH (2015). Dopamine prediction errors in reward learning and addiction: from theory to neural circuitry. Neuron 88: $247-263$.

Kelley AE (2004). Ventral striatal control of appetitive motivation: role in ingestive behavior and reward-related learning. Neurosci Biobehav Rev 27: 765-776.

Kravitz AV, Tye LD, Kreitzer AC (2012). Distinct roles for direct and indirect pathway striatal neurons in reinforcement. Nat Neurosci 15: 816-818.

Loureiro M, Renard J, Zunder J, Laviolette SR (2015). Hippocampal cannabinoid transmission modulates dopamine neuron activity: impact on rewarding memory formation and social interaction. Neuropsychopharmacology 40: 1436-1447.

Niesink RJ, Van Ree JM (1989). Involvement of opioid and dopaminergic systems in isolation-induced pinning and social grooming of young rats. Neuropharmacology 28: 411-418.

Normansell L, Panksepp J (1990). Effects of morphine and naloxone on play-rewarded spatial discrimination in juvenile rats. Dev Psychobiol 23: 75-83.

Panksepp J (1993). Rough and tumble play: a fundamental brain process. In: MacDonald K (ed). Parent-Child Play. SUNY Press: Albany, pp 147-184.

Panksepp J, Siviy S, Normansell L (1984). The psychobiology of play: theoretical and methodological perspectives. Neurosci Biobehav Rev 8: 465-492.

Pellis S, Pellis V (2009). The Playful Brain: Venturing to the Limits of Neuroscience. Oneworld Publications: Oxford, UK.

Pellis SM, Castaneda E, McKenna MM, Tran-Nguyen LT, Whishaw IQ (1993). The role of the striatum in organizing sequences of play fighting in neonatally dopamine-depleted rats. Neurosci Lett 158: 13-15.

Pierce RC, Kumaresan V (2006). The mesolimbic dopamine system: the final common pathway for the reinforcing effect of drugs of abuse? Neurosci Biobehav Rev 30: 215-238.

Robinson DL, Heien ML, Wightman RM (2002). Frequency of dopamine concentration transients increases in dorsal and ventral striatum of male rats during introduction of conspecifics. $J$ Neurosci 22: 10477-10486.

Robinson DL, Zitzman DL, Smith KJ, Spear LP (2011). Fast dopamine release events in the nucleus accumbens of early adolescent rats. Neuroscience 176: 296-307.

Rodriguez-Arias M, Pinazo J, Minarro J, Stinus L (1999). Effects of SCH 23390, raclopride, and haloperidol on morphine withdrawalinduced aggression in male mice. Pharmacol Biochem Behav 64: 123-130.

Salamone JD, Correa M (2012). The mysterious motivational functions of mesolimbic dopamine. Neuron 76: 470-485.

Siviy SM (1998). Neurobiological substrates of play behavior: glimpses into the structure and function of mammalian playfulness. In: Bekoff M, Byers JA (eds). Animal Play: Evolutionary, Comparative, and Ecological Perspectives. Cambridge University Press: Cambridge, pp 221-242.

Siviy SM, Crawford CA, Akopian G, Walsh JP (2011). Dysfunctional play and dopamine physiology in the Fischer 344 rat. Behav Brain Res 220: 294-304.

Siviy SM, Fleischhauer AE, Kerrigan LA, Kuhlman SJ (1996). D2 dopamine receptor involvement in the rough-and-tumble play behavior of juvenile rats. Behav Neurosci 110: 1168-1176.
Trezza V, Baarendse PJ, Vanderschuren LJMJ (2010). The pleasures of play: pharmacological insights into social reward mechanisms. Trends Pharmacol Sci 31: 463-469.

Trezza V, Damsteegt R, Achterberg EJM, Vanderschuren LJMJ (2011). Nucleus accumbens mu-opioid receptors mediate social reward. J Neurosci 31: 6362-6370.

Trezza V, Damsteegt R, Manduca A, Petrosino S, Van Kerkhof LW, Pasterkamp RJ et al (2012). Endocannabinoids in amygdala and nucleus accumbens mediate social play reward in adolescent rats. J Neurosci 32: 14899-14908.

Trezza V, Damsteegt R, Vanderschuren LJMJ (2009). Conditioned place preference induced by social play behavior: parametrics, extinction, reinstatement and disruption by methylphenidate. Eur Neuropsychopharmacol 19: 659-669.

Trezza V, Vanderschuren LJMJ (2008). Bidirectional cannabinoid modulation of social behavior in adolescent rats. Psychopharmacology (Berl) 197: 217-227.

Trezza V, Vanderschuren LJMJ (2009). Divergent effects of anandamide transporter inhibitors with different target selectivity on social play behavior in adolescent rats. J Pharmacol Exp Ther 328: $343-350$

van Furth WR, Wolterink G, van Ree JM (1995). Regulation of masculine sexual behavior: involvement of brain opioids and dopamine. Brain Res Brain Res Rev 21: 162-184.

van Kerkhof LW, Damsteegt R, Trezza V, Voorn P, Vanderschuren LJMJ (2013). Social play behavior in adolescent rats is mediated by functional activity in medial prefrontal cortex and striatum. Neuropsychopharmacology 38: 1899-1909.

van Kerkhof LW, Trezza V, Mulder T, Gao P, Voorn P, Vanderschuren LJMJ (2014). Cellular activation in limbic brain systems during social play behaviour in rats. Brain Struct Funct 219: 1181-1211.

van Ree JM, Gerrits MA, Vanderschuren LJMJ (1999). Opioids, reward and addiction: an encounter of biology, psychology, and medicine. Pharmacol Rev 51: 341-396.

Vanderschuren LJMJ, Niesink RJ, Spruijt BM, Van Ree JM (1995a). Effects of morphine on different aspects of social play in juvenile rats. Psychopharmacology (Berl) 117: 225-231.

Vanderschuren LJMJ, Stein EA, Wiegant VM, Van Ree JM (1995b). Social play alters regional brain opioid receptor binding in juvenile rats. Brain Res 680: 148-156.

Vanderschuren LJMJ, Trezza V, Griffioen-Roose S, Schiepers OJ, Van Leeuwen N, De Vries TJ et al (2008). Methylphenidate disrupts social play behavior in adolescent rats. Neuropsychopharmacology 33: 2946-2956.

Volkow ND, Morales M (2015). The brain on drugs: from reward to addiction. Cell 162: 712-725.

Voorn P, Vanderschuren LJMJ, Groenewegen HJ, Robbins TW, Pennartz CMA (2004). Putting a spin on the dorsal-ventral divide of the striatum. Trends Neurosci 27: 468-474.

Whitaker LR, Degoulet M, Morikawa H (2013). Social deprivation enhances VTA synaptic plasticity and drug-induced contextual learning. Neuron 77: 335-345.

Yorgason JT, Calipari ES, Ferris MJ, Karkhanis AN, Fordahl SC, Weiner JL et al (2016). Social isolation rearing increases dopamine uptake and psychostimulant potency in the striatum. Neuropharmacology 101: 471-479.

Yorgason JT, España RA, Konstantopoulos JK, Weiner JL, Jones SR (2013). Enduring increases in anxiety-like behavior and rapid nucleus accumbens dopamine signaling in socially isolated rats. Eur J Neurosci 37: 1022-1031.

Young LJ, Wang Z (2004). The neurobiology of pair bonding. Nat Neurosci 7: 1048-1054.

Supplementary Information accompanies the paper on the Neuropsychopharmacology website (http://www.nature.com/npp) 